\title{
Zhang Jian and Modern Nantong Architecture
}

\author{
Zenglin Guo a *, Qingzhou Wu \\ Faculty of Architecture, South China University of Technology, China \\ *, a guoart@163.com
}

\begin{abstract}
In 2002, through his investigation and study of Nantong, Wu Liangyong put forward the proposition of "the first city of modern China" in Nantong. This has given the society a new understanding of the cause of building the city in Nantong in the modern times led by Zhang Jian. After a brilliant development from the founding of the Dasheng Cotton Mill in 1895 to the death of Zhang Jian in 1926, Nantong was creatively managed by Zhang Jian. Nantong has also changed from a feudal traditional city to a modern one, creating countless first ones. With the great development of national capital, the modern Nantong city building movement has sprung up a large number of new buildings. This paper takes the achievements of modern Nantong City as an example and tries to discuss the development and evolution of modern Nantong architecture. Furthermore, it summarizes and refines the characteristics of architecture in this period, especially puts forward feasible protection strategies for the present existing architectural heritage and finds out the contents that can be used for reference to our urban construction and architectural design today.
\end{abstract}

Keywords: Zhang Jian; Nantong in modern times; Architecture.

\section{张謇与近代南通建筑}

\author{
国增林，吴庆洲 \\ 华南理工大学建筑学院, 中国
}

摘 要: 2002年吴良锯先生通过对南通的调查和研究, 提出了南通 “中国近代第一城” 的命题, 使得社会对张謇领导的近代南通建城事业有了新的认识。近代南通经过了从1895年大生纱厂 创建到1926年张謇去世30年的辉煌发展历程, 在张謇创造性的经营之下, 南通也由一个封建 意义上传统城市变成了一个近代化城市, 创造了无数个第一。伴随着民族资本的大发展而兴 起的近代南通建城运动, 涌现了大量的新式建筑, 并培养了第一代中国本土的建筑师, 在中 国近代建筑史的发展上留下了浓墨重彩的篇章。本文以近代南通城建筑成果为案例, 试图对 近代南通建筑发展和演变进行探讨, 并进一步总结和提炼这一时期建筑的特点, 挖掘出能对 我们今天的城市建设及建筑设计有借鉴意义的内容。

关键词: 张謇; 近代南通; 建筑。

\section{1. 前言}

一百多年前, 张謇主导和经营近代南通建城事业, 在短短的 30 年间使南通由一个封建小城发展成为长江下游重 要的工商业城市, 在民国时期还获得 “模范县” 的称号, 南通城也成为中国近代城市建设史上一个重要而特殊 的案例。经济发展推动着社会进步, “甲午战后, 民族资本主义有了有了初步发展, 第一次世界大战期间, 民 族资本主义有了进一步的发展。南通、济南、无锡等城市新的工业区也在这时期兴起” [1]。但是, 南通又与当 时国内新兴起城市有所区别, 吴良镛先生曾评价: “南通是中国早期现代化的产物, 它不同于租界、商埠或列 强占领下发展起来的城市, 是中国人基于中国理念, 比较自觉地、有一定创造性地、通过较为全面的规划、建 设、经营的第一个有代表性的城市” [2]。因此, 一方面近代南通城具有较强的地域性特征, 另一方面又无处不 反映着张謇个人的思想光辉，在城市规划和建筑形态方面体现的尤为明显：城市规划方面体现为 “一城三镇” 的空间格局; 建筑设计上体现为依托传统并 “近学上海、远学日本及西方” 的中西融合特征。《中国建筑史》及 《20 世纪中国建筑》均有刊载近代南通建筑, 可见近代南通建筑在中国建筑史的重要地位。总体而言, 近代南 通的建筑实践历时时间长, 建筑规模及数量庞大, 建筑类型极其丰富, 建筑形态及样式融汇中西, 建筑理念因 地制宜，有中国本土培养的设计师参与，诸多特点造就了近代南通建筑实践的重要价值。 


\section{2. 张謇建筑思想的渊源}

应该说张謇的建筑思想并非是突然就有的, 而是借由成长过程中不断的实践, 逐步提升和发展而成的。张謇 (见 图 1-1), 字季直, 晚年号啬翁, 清咸丰三年 (1853 年) 出生于江苏海门直隶厅一户小农之家。清同治七年 (1868 年) 考中秀才, 之后经过了漫长的约 30 年科举之路才于光绪二十年 (1894 年) 考中状元, 后来弃官从商, 秉持 “父教育母实业” 的理念, 办厂兴学及推进各项社会事业, 开启了近代南通 30 年的发展历程。

\section{3. 少年筑屋兴趣}

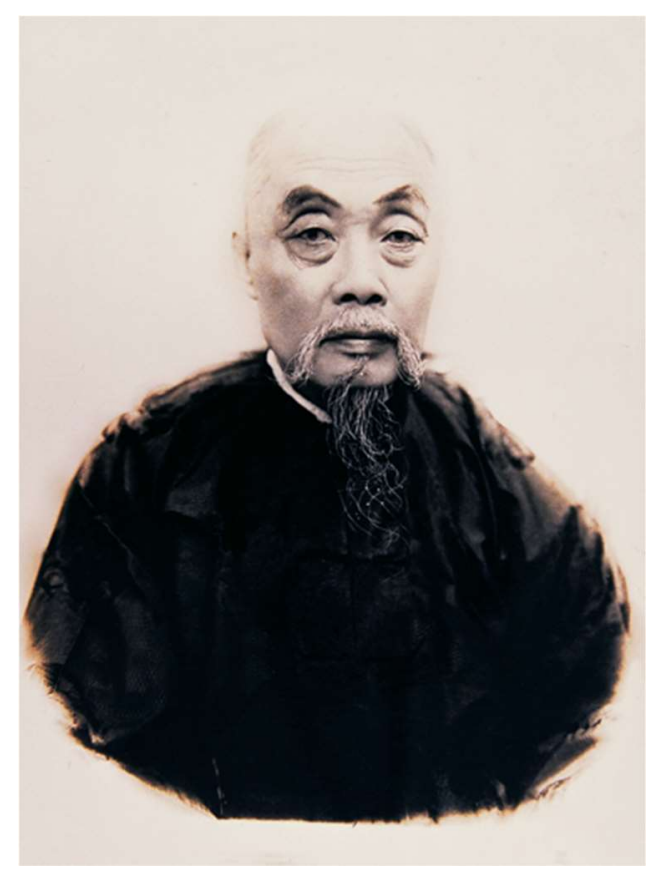

图 1 张謇晚年像

（来源 张謇纪念馆）

张謇少年时期就有两大爱好, 即建筑和植树。张謇之子张孝若的《南通张季直先生传记》中就记载到: “我父 生平有二件嗜好，一件是建筑。他幼时就有建筑的兴味。一件是种树” [3]。张謇之孙张绪武的《我的祖父张謇》 一书中也有记载: “家中事物, 全靠自己来做, 如盖房子, 从划线、打地基到砌砖、上梁、盖顶, 全由他（张 绪武曾祖张彭年) 领着祖父 (张謇) 和三祖父 (张誓) 亲手完成” [4]。由以上记述可见, 张謇青少年时期在参 与造房活动中积累了一定的经验, 并对建房产生了兴趣。见识的积累和实践经验的丰富, 奠定了他以后主导近 代南通的建城事业重要的基础作用, 张謇能毫不费力第开具建房的材料清单, 在他致当时的建筑商吴晓江的一 封信可见一斑: “前开去长桥南市房楼六幢高、深、广尺寸, 托为照此配料, 未得复讯, 不知已配完否? 如已配 完, 即可札排送来。” 可见当时张謇对于造房已是驾轻就熟, 能合理地规划建筑尺度并准确计算用料, 练就了 过硬的技术能力。

\section{4. 张寒主导的建筑营造概况}

张謇在通州师范学校开学演讲中说: “欲雪其耻, 而不讲求学问则无资; 欲求学问, 而不求普及国民之教育则 无兴; 欲教育普及国民。而不求师则无导。”张謇认为自强的道路在普及教育, 在没有资本的情况下, 以兴办 实业来资助教育。沿着这条预设的发展路径, 公认张謇经营近代南通的起始是光绪二十一年 (1895 年) 筹设大 生纱厂, 大生纱厂最终选址在唐家闸陶朱坝， “英商汤姆设计、上海曹协顺营造厂承造的大生纱厂，厂房为砖 木结构, 完全英式” [1]。光绪二十五年 (1899 年) 大生纱厂建成投产后, 发展顺利, 获利颇丰, 为兴办其他实 业及各项事业奠定了经济基础。

2.1. 近代南通建筑的主要类型

张謇兴办的实业中工业部分; 棉纺织丝织绣织、民用制造、机械铸造、食品加工; 交通运输; 金融商贸; 电力通 信; 仓储; 渔业（见表 1-2）。

张謇兴办的实业中教育部分: 师范教育; 幼儿教育; 基础教育; 职业高等教育; 特殊教育; 社会教育（见表 $1-$ 1)。

除以上工业和教育之外, 为解决纱厂原材料问题, 大力发展垦牧公司, 开剭滨海沿江荒滩, 张謇生前参与创办 的垦牧公司数量达到 77 家。 
表1 张謇经营实业类型及数量统计

\begin{tabular}{|c|c|c|c|}
\hline 项目 & 序号 & 名称 & 数量 (家) \\
\hline \multirow{5}{*}{} & 1 & 棉纺织丝织绣织 & 16 \\
\cline { 2 - 4 } & 2 & 民用制造 & 17 \\
\cline { 2 - 4 } & 3 & 机械铸造 & 2 \\
\cline { 2 - 4 } & 4 & 食品加工 & 5 \\
\cline { 2 - 4 } & 5 & 交通运输 & 24 \\
\cline { 2 - 4 } & 6 & 金融商贸 & 72 \\
\cline { 2 - 4 } & 7 & 电力通信 & 9 \\
\cline { 2 - 4 } & 8 & 仓储 & 2 \\
\cline { 2 - 4 } & 9 & 渔业 & 124 \\
\hline
\end{tabular}

（来源 作者自绘）

表 2 张謇兴办教育类型及数量统计

\begin{tabular}{|c|c|c|c|}
\hline 项目 & 序号 & 名称 & 数量 (所) \\
\hline \multirow{5}{*}{ 教育 } & 1 & 师范教育 & 5 \\
\cline { 2 - 4 } & 2 & 幼儿教育 & 4 \\
\cline { 2 - 4 } & 3 & 基础教育 & 15 \\
\cline { 2 - 4 } & 4 & 职业高等教育 & 1 \\
\cline { 2 - 4 } & 5 & 特殊教育 & 7 \\
\cline { 2 - 4 } & 6 & 社会教育 & 50 \\
\hline
\end{tabular}

（来源 作者自绘）

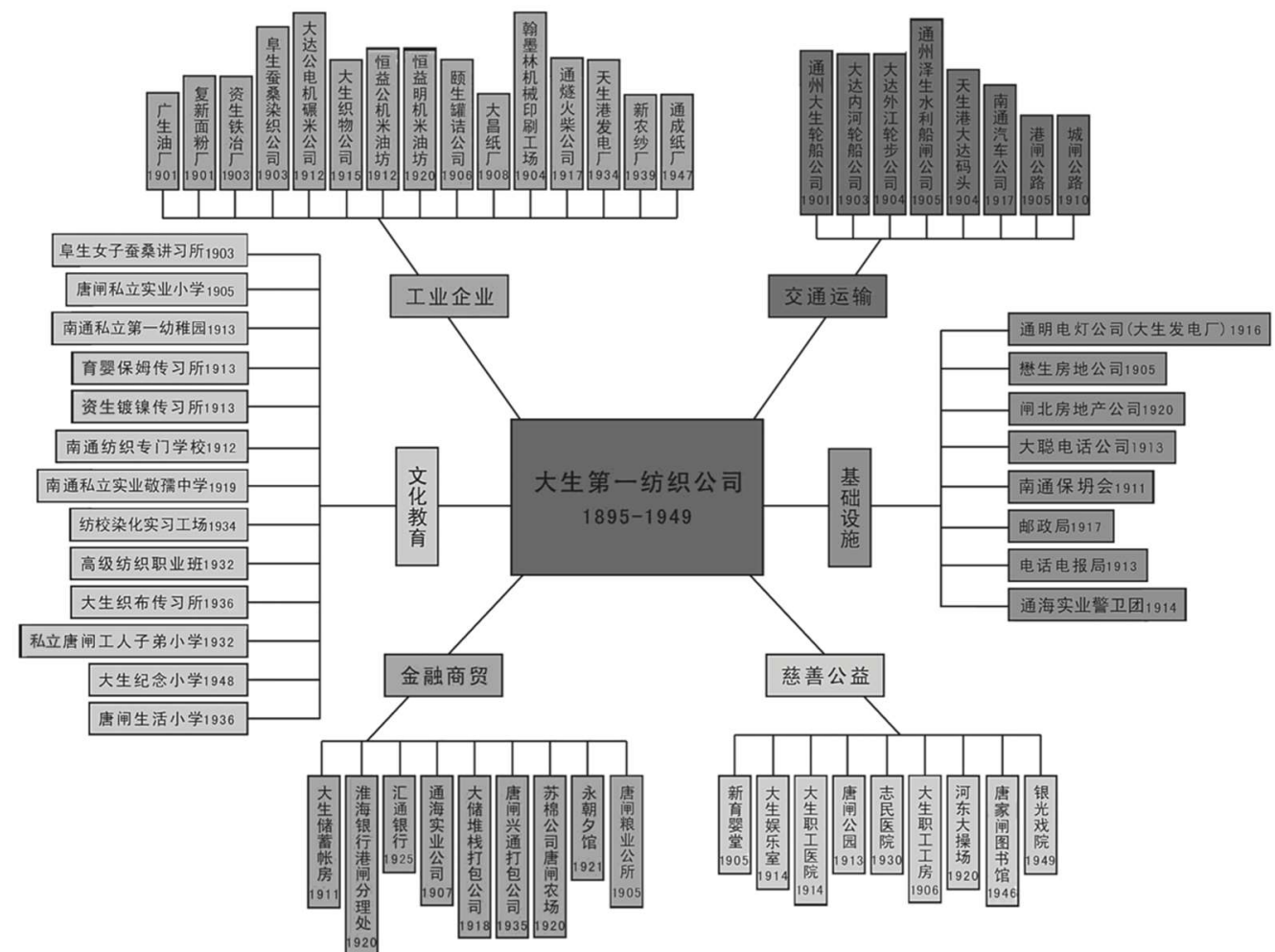

图 2 大生资本集团组织系统图 （来源 张謇纪念馆）

对张謇主导经营南通时期的建筑成就进行梳理并分类, 有助于明确个体建筑的基本概念及其在总体研究中的具 体地位和作用, 从而能够在宏观上加强对于那个特定时期建筑活动的认识。在建筑的分类上主要有四种方式: 
（1）按时间阶段划分;（2）按使用功能划分; (3) 按聚合形态划分; (4) 按空间区位划分。就张謇时期近代 南通的实践来说, 其建设活动从开始到结束, 具有历时性的特征, 不同时期的建设活动在内容上具有相似性, 以时间分期为分类方式，存在重复性的弊端。张謇对于南通的总体设想是建成一个 “新新世界” 的范本，因此 综合各项事业呈现 “小而丰” 的特点, 在建筑类型上是比较全面的, 按照功能属性进行划分较为符合张謇的建 城思想。

2.2. 近代南通建筑的主要特征

近代南通建筑的分布与南通 “一城三镇” 的空间格局具有直接的相关性，可以说前后延续 30 年的建筑活动塑造 了 “一城三镇” 新的面貌。各式建筑也与张謇主导的 “南通自治” 范本的要求相适应, 类型丰富而且造型新颖。 近代南通的建筑活动体现了极强的 “地域性” , 产业的需要、张謇自身的要求、基于地方的建筑传统的继承, 形成了近代南通建筑的特色。

(1) 建筑分布适应 “一城三镇” 的要求

唐闸工业区建设: 张謇开始经营南通时, 选择远离老城约 7 公里的唐家闸陶朱坝作为大生纱厂的厂址, 开启了 将唐闸建设成为工业区的历程。围绕着大生纱厂，衍生构建了一个工业产业链系统。“唐闸在整体布局上，乃 至于与南通主城区, 与港口区间的相对位置, 皆安排合理, 具有良好的发展空间” [4]。分布上厂区 (大生纱厂、 复兴面粉厂、广生油脂厂、资生铁冶厂等配套相关企业）、住宅区（老工房、南工房、东工房等工人用房）、商 业区（机米坊等）相分离, 形成互补却互不干扰的空间格局, 配套教育机构如纺织专门学校、各类小学, 休闲 娱乐空间如唐闸公园等，交通方面如各类码头、渡口，公共配套如水利公司、轮船公司等。

五山风景区建设: 在南通城南掀起建设高潮之外, 张謇还大力开辟五山风景区。除了一部分别墅, 还修建了很 多景点设施: 林溪精舍、东奥山庄、西山村庐、虞楼、我马楼、介山楼、独秀阁、后张榭、古有有亭、观音院赵 绘沈绣楼等，依托自然山林，广植林木，新增建筑及设施，营造了丰富的景观层次。

天生港港口建设：随着唐闸工业区初步成型，为尽快解决货物和所需物资的进出交通问题，建设货物吞吐码头 就被提上日程。张謇沿长江考察姚港、任港、芦泾港之后, 看中天生港有内河通唐闸, 因此开始了天生港的建 设。光绪三十年（1904 年）大达轮步公司的成立, 打通了南通天生港和上海十六铺的交通运输, 成为通沪间第 一条航线。为了进一步使唐闸借道天生港连接上海, 张謇创办的泽生外港水利公司展开了港闸河的清淤工作。 后期有相关建设如设立大生电厂、老点灯厂、通煫火柴厂等，天生港也逐渐发展成为一个工商业重镇。

(2) 建筑风格上 “中学为体、西学为用”

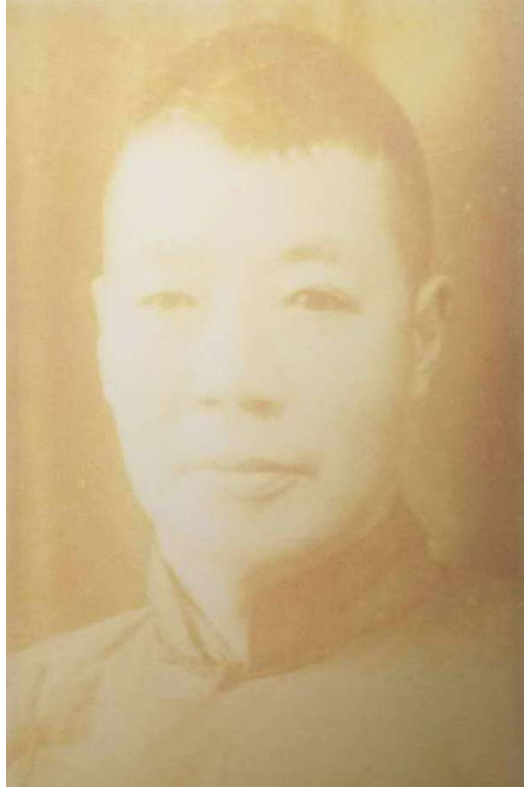

图3 青年孙支厦像 （来源 南通博物苑）

考察张謇的涉外足迹，一是光绪八年（1882 年）在朝鲜爆发 “壬午兵变” 时随吴长庆入朝到 过汉城。二是光绪二十九年 (1903 年) 应邀参观日本第五次国内劝业博览会, 对日本 70 天的 考察。但是南通城市及建筑却呈现 “中欧混合的都市化”倾向，一些外国人甚至称它为“远 东威尼斯” [4]。可以说主要由建筑物构成和影响的近代南通城新式很大程度上区别于旧城市。 一方面这是由张謇兴办的近代工业及公共建筑所决定的, 另一方面也是张謇为使建筑服务“地 方自治” 主动选择的结果。如大生纱厂选择英国设计师来主导设计; 江苏省咨议局大楼（见 图 1-11）由孙支厦赴日详细测绘日本 “帝国议院” 后按日本的法国文艺复兴建筑形式进行了 设计; 张謇建于民国三年 (1915 年) 的濠南别业的设计, 是参考北京建于光绪三十四年 (1908 
年) 的清皇室行宫畅观楼。特别是张謇培养的本土建筑师孙支厦于宣统元年（1909 年）设计 江苏省咨议局大楼后, 大部分的建筑设计任务都由他完成, 建筑大部分参考西式建筑的样式 进行设计。但新兴建筑并非全盘西化, 而是很好的结合地方建筑传统的资源, 根据新的功能 需求展开创新设计：如大生纱厂（大生一厂、二厂、三厂、八厂）配套的工房、张謇的住宅濠 阳小筑及位于狼山风景区的别墅等、颐生酿造公司、翰墨林印书局等。

（3）在建筑中强化门头造型

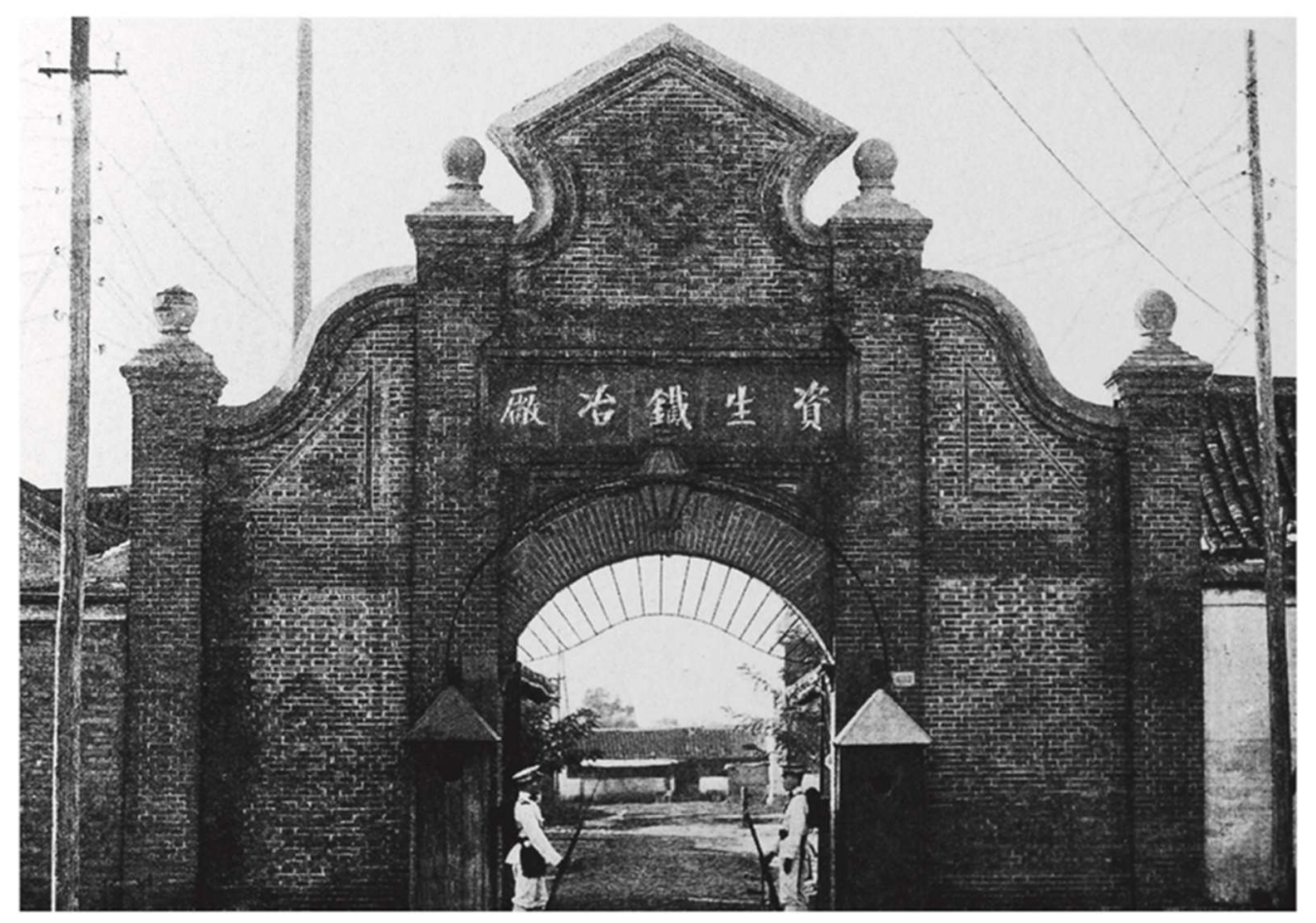

图 4 资生冶铁厂表门

（来源 张謇纪念馆）

上海海关税务司、英国人戈登・劳德在 1921 年 12 月底给英国政府的《海关十年报告》中称 道: “......南通州与中国内地城市不同, 除街道比较狭窄外, 一切都像上海的公共租界。市 内有各种商, 西式楼房到处可见。张謇是使通州发展成为一座中国模范城市的主要人物”。 从记述中可见，张謇规划经营南通 “新

新世界” 时吸收借鉴西方建筑文化并应用到具体的建筑实践中。历时 30 年的建设成果中西式 的门头 (见图 1-13) 作为一种符号体现在建筑立面上, 得到了非常普遍的运用。（1）从门头 的功能上讲, 作为建筑主要的出入口, 强化了识别性, 而且根据建筑不同的功能属性, 或繁 或简都具有较强的装饰性, 同时也表现了国人强调 “门脸” 的传统文化诉求; (2) 在具体的 应用层面, 一是门头作为一个独立的标志物, 二是门头与围墙结合强化主出入口的 “形象”, 三是门头与建筑结合成为建筑立面的一部分; (3) 造型规律方面, 在门头比例上大多按高宽 2: 1 来设计, 在高度上有一层、二层及三层之分, 在造型上一般分为曲线和三角形山花两种 并根据建筑要求不同做出各种样式变化。张謇经营南通时期建筑的门头造型是特定历史时期 特定需求下的产物, 在具体应用过程中体现了功能、形式与审美的有机结合, 并呈现了外来 文化适应地方传统之后成熟的文化融合。

\section{5. 结语}

近代南通的建筑营造活动, 是与张謇发展地方生产力的需要相适应的, 也与张謇推动教育及 社会慈善事业有着密切的联系。近代南通的建筑数量之大、类型之广使其在中国近代城市发 展史上占有独特的位置。总体而言, 近代南通的建筑成果是张謇秉持并推动的 “地方自治” 事业的不可分割的一部分, 同时基于传统借鉴西方文化的建筑也构成了近代南通城市的面貌。 
与此同时，在这一特定的历史时期还培养出中国本土的建筑师，在孙支厦之后才出现近代意 义上的、建筑学专业出身的建筑师。南通城至今还存有大量百年前张謇时期的建筑遗留, 研 究近代南通的建城成就, 做好这些特定时期建筑文化遗产的保护工作，也是南通进一步催动 城市发展的文化基点。

\section{References}

[1]. by Chinese Architecture History Compilation Group, Chinese Architecture History (2nd edition) [M]. Beijing: China Architecture and Building Press. 1986: Page 213

[2]. by Nantong Bureau of Culture, Nantong “The First City of Modern China” Research Collection [M]. Nantong: 2003

[3]. by Zhang Xiaoruo, Biography of Mr. Zhang Jizhi, [M]. Nantong: Zhang Jian Research Center (Reprinted). 2014: Page 327 to 330

[4]. by Yu Lizi, Oriental Utopia - Modern Nantong [M]. Beijing: People's Press, 2007. Page 35 